\title{
ATMOSFERA MODIFICADA E 1-METILCICLOPROPENO NA CONSERVAÇÃO PÓS- COLHEITA DE KIWIS CV. BRUNO ${ }^{1}$
}

\author{
LEANDRO CAMARGO NEVES ${ }^{2}$, ADRIANA CORRENT ${ }^{3}$, LEONOR MARINI ${ }^{3}$, LUCIANO LUCCHETTA ${ }^{3}$,MARCIO \\ ROGGIA ZANUZZO' ${ }^{3}$, EMERSON DIAS GONÇALVES ${ }^{4}$, JOCEMAR ZANATTA ${ }^{5}$; FERNANDO RUFFINO CANTILLANO 6 \\ CESAR VALMOR ROMBALDI ${ }^{7}$
}

\begin{abstract}
RESUMO - Neste trabalho avaliou-se, em kiwis da cv Bruno, a ação do 1-Metilciclopropeno (1-MCP), na concentração de 625 ppb, associado ou não à atmosfera modificada gerada com o emprego de embalagem de polietileno de baixa densidade (PEBD), de $22 \mu \mathrm{m}$. Os tratamentos testados foram: T1, controle (sem embalagem e 1-MCP); T2, sem embalagem com 1-MCP; T3, com embalagem de PEBD sem 1-MCP; T4, embalagem de PEBD mais o 1$\mathrm{MCP}$, sendo após armazenados em câmara fria a $-0,5 \pm 0,5^{\circ} \mathrm{C}$ e $95 \pm 5 \%$ de umidade relativa (U.R.). As avaliações foram realizadas após o préresfriamento, aos 45 dias, $45+5$ dias $\left(22 \pm 3^{\circ} \mathrm{C}\right.$ e $75 \pm 5 \%$ de U.R. $), 90$ dias e $90+5$ dias $\left(22 \pm 3^{\circ} \mathrm{C}\right.$ e $75 \pm 5 \%$ de U.R.). As variáveis analisadas foram: firmeza de polpa (FP), sólidos totais (ST), acidez titulável (AT), concentração de etileno e de $\mathrm{CO}_{2}$ e análise sensorial (somente ao final do experimento). A maior firmeza de polpa e acidez titulável, o menor conteúdo de sólidos totais, as menores concentrações de etileno e $\mathrm{CO}_{2}$ e a melhor aceitabilidade pelos julgadores foi obtida com os frutos acondicionadas em PEBD de $22 \mu \mathrm{m}$ e tratadas com 1-MCP.
\end{abstract}

Palavras-chave: Pós-colheita, etileno, armazenamento, qualidade.

\section{MODIFIED ATMOSPHERE AND 1-METHYLCICLOPROPENE ON POSTHARVEST CONSERVATION OF KIWIS CV. BRUNO}

ABSTRACT - In this work was evaluated, for kiwis cv. Bruno, the Methylcyclopropene action (1-MCP), in concentration of 625 ppb, associated or not with modified atmosphere (MA) using low density polyethylene bags (LDPE) of $22 \mu \mathrm{m}$. The following treatments were tested: T1: control (no bags and 1-MCP); T2 - no bags with 1-MCP; T3 - LDPE bags no 1-MCP; T4 - LDPE bags and 1-MCP, then they were stored in cold chamber at $0,5 \pm 0,5^{\circ} \mathrm{C}$ and $95 \pm 5 \%$ of RH for 45 or 90 days. The fruits were evaluated after pre-cooling, 45 days, $45+5$ days $\left(22 \pm 3^{\circ} \mathrm{C}\right.$ and $75 \pm 5 \%$ of RH. $), 90$ days and $90+5$ days $\left(22 \pm 3^{\circ} \mathrm{C}\right.$ and $75 \pm 5 \%$ of RH.). The parameters analyzed were: pulp firmness (PF), total solids (TS), titritable acidity (TA), ethylene and $\mathrm{CO}_{2}$ concentration, and sensorial analyzes (only in the end of the experiment). The largest pulp firmness and titritable acidity, the smaller content of total soluble, the smaller concentration of ethylene and $\mathrm{CO}_{2}$ and the better acceptability for the taste panel was obtained with the fruits stored in LDPE of $22 \mu \mathrm{m}$ and treated with 1-MCP.

Index Terms: Postharvest, ethylene, stored, quality.

\section{INTRODUÇÃO}

No Brasil, segundo Souza et al. (1996), a região Sul, em especial os Estados do Rio Grande do Sul, com 260 hectares e Santa Catarina, com 175 hectares, apresentam-se como os maiores produtores de kiwi, com destaque principal para a cultivar Bruno.

A cultivar Bruno caracteriza-se por apresentar plantas medianamente vigorosas e produtivas. Os frutos são cilíndricos alongados, cobertos de pêlos densos, curtos e cheios de cerdas que facilitam a identificação entre os de outras cultivares. A polpa é de sabor doce-acidulado, agradável, com maior concentração de vitamina $\mathrm{C}$ do que as demais variedades. A maturação é precoce, sendo possível o armazenamento refrigerado. Porém é pouco resistente à manipulação e ao transporte (Simão, 1998).

A vida pós-colheita dos frutos, dentre outras tecnologias, pode ser estendida pelo armazenamento refrigerado (AR), uso de atmosferas modificadas (AM), através de filmes de PEBD (Mosca, 1999) e por atmosferas controladas (AC), contendo níveis elevados de dióxido de carbono (Smith, 1992) e baixas concentrações de etileno (Willis \& Kim, 1995). Vários inibidores da ação do etileno, tais como o tiossulfato de prata (Cameron \& Reid, 1981) e ciclopropenos (Sisler \& Serek, 1997) são efetivos antagonistas da ação de etileno. Os riscos de contaminação do meio ambiente e/ou toxidez tem restringido o uso desses compostos.

Segundo Warrington \& Weston (1990), o aspecto mais relevante da fisiologia pós-colheita do kiwi é a sua alta sensibilidade ao etileno. Concentrações de $0,1 \mu \mathrm{L} . \mathrm{L}^{-1}$ na atmosfera de armazenagem reduzem a vida de armazenamento dos frutos (Sisler \& Serek, 1997). Um dos principais efeitos do etileno sobre o kiwi é o incremento na velocidade de perda da firmeza de polpa dos frutos.

Tem sido demonstrado que a aplicação de 1-MCP inibe respostas ao etileno na senescência de flores (Sisler et al., 1996) e na maturação de frutos tais como bananas (Golding et al., 1998), maçãs (Fan et al., 1999b), pêras (Fan et al., 1999c). Acredita-se que o 1-MCP previne respostas das células ao etileno pela sua interação com o receptor do etileno (Sisler \& Serek, 1997). Aparentemente, o 1-MCP possui maior afinidade que o etileno ao sítio receptor e inibe a ação do etileno não competitivamente, permanecendo ligado ao receptor por longos períodos (Serek et al., 1994). Embora o 1-MCP seja um gás, tem sido formulado em pó, com o nome comercial de EthylBloc, que libera 1MCP quando misturado com uma base diluidora (Fan et al., 1999a).

A armazenagem em AM é uma tecnologia versátil que é aplicada para uma grande quantidade de frutos e hortaliças (Jiang et al., 1999). Segundo Neves et al. (2002) e Mosca (1999), o uso de embalagens de PEBD, associada ao AR, preserva a integridade dos frutos, possibilitando uma melhor manutenção dos atributos sensoriais dos mesmos.

Com base nas informações descritas, o trabalho tem por objetivo avaliar a utilização de embalagens de PEBD e o uso do 1-MCP, na conservação de kiwis cv. Bruno.

\section{MATERIAL EMÉTODOS}

O experimento foi instalado nas dependências da empresa KIWIS'TRIN LTDA-Farroupilha/RS, na safra 2001, e as análises foram realizadas no Laboratório de Biotecnologia de Alimentos da Faculdade de Agronomia Eliseu Maciel - UFPel. Na colheita, os frutos

\footnotetext{
(Trabalho 053/2003). Recebido: 21/04/2003. Aceito para publicação: 05/11/2003.

${ }^{2}$ UFRGS - Doutorando em Fitotecnia, C.P. 776, CEP 91501-970, Porto Alegre/RS. e-mail: rapelbtu@hotmail.com

${ }_{3}^{3}$ UFPel - Mestrando em Ciência e Tecnologia Agroindustrial, C.P. 354, CEP 96010-900, Pelotas/RS. e-mail:adrix@ufpel.tche.br

${ }^{4}$ UFPel - Doutorando em Fruticultura, C.P. 354, CEP 96010-900, Pelotas/RS. e-mail: gonçalves@ufpel.tche.br

${ }^{5}$ UFPel - Bolsista do Dep ${ }^{\text {to }}$ de Ciência e Tecnologia Agroindustrial, C.P. 354, CEP 96010-900, Pelotas/RS. e-mail:zanatta@ufpel.tche.br

${ }^{6}$ EMBRAPA/Clima Temperado - Eng. Agr. Pesquisador III, C.P. 403, CEP 96001-970, Pelotas/RS. e-mail: cantillano@embrapa.com.br

${ }^{7}$ UFPel - Prof. Dr. Dep ${ }^{\text {to }}$ de Ciência e Tecnologia Agroindustrial, C.P. 354, CEP 96010-900, Pelotas/RS. e-mail:cesarvrf@ufpel.tche.br
} 
apresentavam teor médio de ST de $6,3{ }^{\circ}$ Brix, FP média de $73 \mathrm{~N}$ e peso médio unitário de $93 \mathrm{~g}$. De maneira geral essas condições são consideradas como adequadas à colheita deste fruto (Legarraga, 1994). O pré-resfriamento foi realizado, em câmara fria, a $0 \pm 0,5^{\circ} \mathrm{Ce} 95 \pm 5 \%$ de U.R., até que a temperatura da polpa dos frutos atingisse $2,5 \pm 0,5^{\circ} \mathrm{C}$. Após, os frutos foram submetidos aos seguintes tratamentos: T1 controle (sem embalagem e 1-MCP); T2 - sem embalagem com 1-MCP; T3 - embalagem de PEBD sem 1-MCP; T4 - embalagem de PEBD mais o 1-MCP.

Nos frutos tratados com o 1-MCP, o produto foi aplicado em câmara hermética de $0,54 \mathrm{~m}^{3}$. Foi utilizado o produto comercial EthylBloc ${ }^{\circledR}$ que contém $3 \%$ do princípio ativo, sendo necessários $25,2 \mathrm{~g}$ do produto comercial diluído em solução de Lauril Sulfato de Sódio $\left(10 \mathrm{~mL}\right.$ e $\left.50^{\circ} \mathrm{C}\right)$, de modo a se conseguir uma concentração de $625 \mathrm{ppb}$. A solução volátil então, foi deixada com os frutos, por $24 \mathrm{~h} \mathrm{a} 22^{\circ} \mathrm{C} \pm 3{ }^{\circ} \mathrm{C}$ e U.R. de $75 \pm 5$ $\%$. Já nos tratamentos submetidos somente à embalagem de PEBD, os frutos foram acondicionados em um número de 15 frutos por embalagem, em sacos de 42 × $22 \mathrm{~cm}$ de largura, com uma espessura de $22 \mu \mathrm{m}$. As embalagens foram termosseladas por seladora comercial Arkop ${ }^{\circledR}$ modelo $\mathrm{TP}-103 / 02$.

No tratamento em que os frutos foram acondicionados em filmes de PEBD e expostos à ação do $1-\mathrm{MCP}$, realizou-se primeiro a exposição dos frutos ao 1-MCP e, em seguida, o acondicionamento nas embalagens.

Os frutos foram então armazenados em câmara frigorífica a $0,5 \pm 0,5^{\circ} \mathrm{C}$ e $95 \pm 5 \%$ de UR. As avaliações físico-químicas foram realizadas logo após o pré-resfriamento, aos 45 dias ( $12 \mathrm{~h}$ após a retirada do AR), $45+5$ dias a $22^{\circ} \mathrm{C} \pm 3{ }^{\circ} \mathrm{C}$ e U.R. de $75 \pm 5 \%$, 90 dias ( $12 \mathrm{~h}$ após a retirada do AR) e $90+5$ dias a $22^{\circ} \mathrm{C} \pm 3{ }^{\circ} \mathrm{C}$ e U.R. de $75 \pm 5 \%$.

As variáveis analisadas foram: firmeza de polpa (FP), por meio de um penetrômetro manual, ponteira de $8 \mathrm{~mm}$ e resultados expressos em N; sólidos totais (ST), através de refratômetro de campo e resultados expressos em ${ }^{\circ}$ Brix; acidez titulável (AT), através de titulometria de neutralização $(\mathrm{NaOH}=0,01 \mathrm{~N})$, ponto de viragem $(\mathrm{pH}=8,2)$ e resultados expressos em Cmol.L ${ }^{-1}$; concentração de $\mathrm{CO}_{2}$ e etileno dentro das embalagens (amostra retirada do espaço livre das embalagens); por cromatografia gasosa, resultados expressos em $\mathrm{kPa}$ e análise sensorial, através de teste de preferência, com 15 julgadores treinados, através de escala hedônica de 5 pontos, variando de gostei muitíssimo (nota 5) a desgostei muitíssimo (nota 1), segundo Moraes (1988).

O delineamento experimental foi o inteiramente casualizado, com esquema fatorial $2 \times 2 \times 5$ (embalagem, 1-MCP e tempo de armazenamento), com 4 tratamentos e 3 repetições (15 frutos por repetição). Os dados foram submetidos à análise de variância e a comparação de médias foi efetuada pelo teste Tukey $(\mathrm{P} \leq 0,05)$. Todos os dados obtidos no trabalho foram avaliados pelo programa StatGraphics.

\section{RESULTADOS E DISCUSSÃO}

Aos 45 dias de AR observou-se um aumento não esperado da FP dos frutos submetidos à embalagem de PEBD, em relação aos valores iniciais encontrados na colheita. Este fato provavelmente é devido à variabilidade intrínseca das amostras. Após 45 dias de

AR, todos os tratamentos sofreram decréscimos normais nos valores de FP (Figura 1). Os frutos acondicionados em embalagens de PEBD com o 1-MCP foram os que menos perderam firmeza, apresentando em todo o período experimental, valores superiores aos demais tratamentos, mesmo após a retirada dos frutos do AR, onde o metabolismo dos frutos retoma a sua velocidade normal, apresentando uma maior suscetibilidade ao amolecimento. Este comportamento pode ser explicado, pelo fato de que a associação entre a embalagem de PEBD e o 1-MCP, resultou em uma redução na velocidade dos processos relacionados à desestruturação dos tecidos celulares, o que colaborou para a preservação da FP. Resultados semelhantes foram obtidos por Jiang et al. (1999), que trabalharam com embalagens de PEBD de $30 \mu \mathrm{m}$ e 1-MCP $(0,05 ; 0,1 ; 0,5$ e $1 \mu \mathrm{L})$, aplicado na pós-colheita de bananas $\mathrm{cv}$.
'Cavedish', onde os autores observaram excelente manutenção dos valores de FP durante 28 dias à temperatura de $20^{\circ} \mathrm{C}$. Kim et al. (2000) e Waclawovsky et al. (2001) também demonstraram que o 1-MCP reduziu o amolecimento de kiwis armazenados a 0 e $20^{\circ} \mathrm{C}$. Ao final do período de simulação de comercialização, os frutos embalados em PEBD com o 1MCP apresentavam uma FP média de $49 \mathrm{~N}$. Este valor é considerado adequado por Legarraga (1994), que considera valores entre 36 e $40 \mathrm{~N}$, como suficientes para o transporte/comercialização dos frutos até o mercado consumidor, sem que haja nenhum comprometimento de sua qualidade.

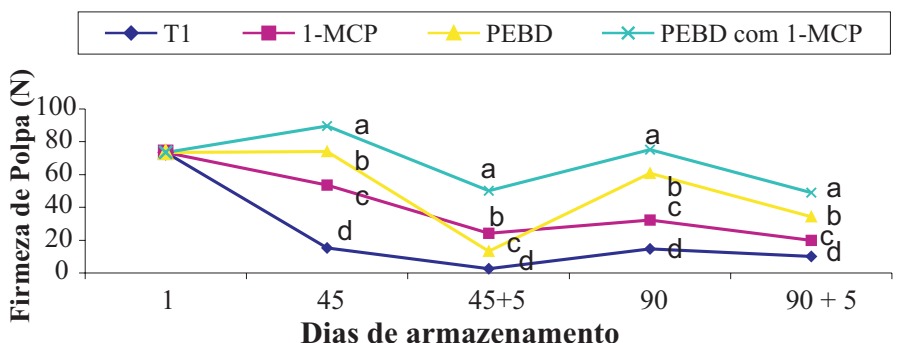

Estatística para uma mesma época de armazenagem, ao nível de 5\% de probabilidade pelo teste de Tukey.

FIGURA 1 - Firmeza de polpa de kiwis cv. Bruno, armazenados 90 dias sob refrigeração a $0 \pm 0,5^{\circ} \mathrm{C}$ e $95 \pm 3 \%$ de UR mais 5 dias de simulação de comercialização a $22 \pm 3^{\circ} \mathrm{C}$ e $75 \pm 5 \%$, Farroupilha/RS-2001.

Pela análise de ST, observa-se que durante o período experimental, ocorreram aumentos graduais no conteúdo de ST de todos os tratamentos (Figura 2). Os frutos controle, ao final do experimento, foram os que tiveram os maiores aumentos, apresentando teores médios de ST na ordem de $15,4^{\circ}$ Brix, ou seja, um aumento de aproximadamente $8^{\circ}$ Brix desde a colheita. Já os frutos acondicionados em embalagens de PEBD com o 1-MCP, apresentaram as menores variações no conteúdo de ST, onde, ao final dos 90 dias de $\mathrm{AR}+5$ dias de comercialização simulada, apresentavam teores médios de $10,3{ }^{\circ}$ Brix, ou seja, uma diferença de aproximadamente $3{ }^{\circ}$ Brix dos teores de ST iniciais. Este resultado difere de alguns autores como Waclawovsky et al. (2001) que, trabalhando com kiwis cv. Bruno, Fan et al. (2002), trabalhando com pêras cv. 'Elberta', Fan et al. (1999a), trabalhando com maçãs cv. 'Ginger Gold', Gala e 'Jonalgold' não observaram diferenças significativas nos teores de ST, quanto ao emprego do 1-MCP. No mesmo experimento, Fan et al. (1999a), agora trabalhando com maçãs cv. 'Golden Delicious' e Fuji, observou um comportamento diferente, onde, frutos tratados com 1-MCP apresentaram maiores conteúdos de ST quando comparados aos frutos não tratados. Embora ainda existam divergências quanto à atuação do 1-MCP nos teores de ST dos frutos, como descrito nos trabalhos acima mencionados, de acordo com os resultados expressos neste experimento, os frutos acondicionados em embalagens de PEBD com 1-MCP, aparentavam estar em estádio menos avançado de amadurecimento quando comparados aos demais tratamentos. Deste modo é demonstrado a eficiência da AM em associação com o 1-MCP, quanto à contenção da velocidade dos processos relacionados ao avanço do amadurecimento.

Com relação à análise de AT, durante o período experimental de 90 dias de $\mathrm{AR}+5$ dias de comercialização simulada, observaram-se reduções nos teores de AT (Figura 3). A velocidade com que isso ocorre está diretamente relacionada com a velocidade do metabolismo (Senter et al., 1991). Maiores decréscimos foram constatados nos frutos do tratamento controle e nos frutos acondicionados em filme de PEBD, onde, a AT passou de 29,91 Cmol. $\mathrm{L}^{-1}$ para aproximadamente $20 \mathrm{Cmol} . \mathrm{L}^{-}$ ${ }^{1}$ ao final do trabalho. Já nos frutos tratados com 1-MCP, com e sem embalagem, foram observadas as menores variações da AT, sendo que ao final do experimento estes frutos apresentavam teores médios de 25,5 Cmol.L-1. Assim, constatou-se que através do uso do 1-MCP pôde- 


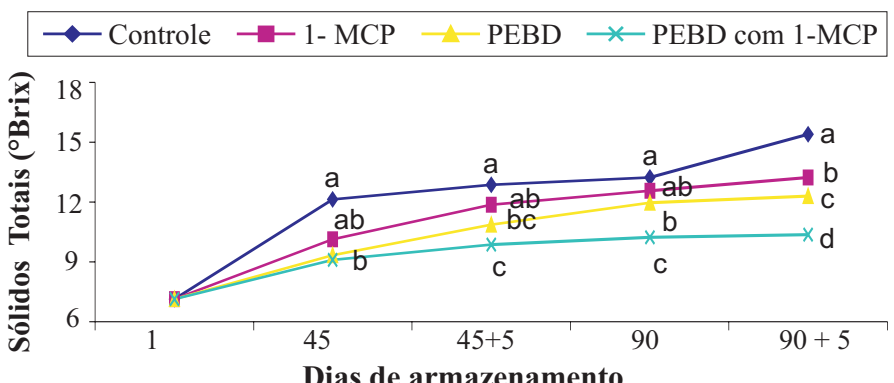

Dias de armazenamento

Estatística para uma mesma época de armazenagem, ao nível de 5\% de probabilidade pelo teste de Tukey.

FIGURA 2 - Sólidos totais de kiwis cv. Bruno, armazenados 90 dias sob refrigeração a $0 \pm 0,5^{\circ} \mathrm{C}$ e $95 \pm 3 \%$ de UR mais 5 dias de simulação de comercialização a $22 \pm 3^{\circ} \mathrm{C}$ e $75 \pm 5 \%$, Farroupilha/RS - 2001 .

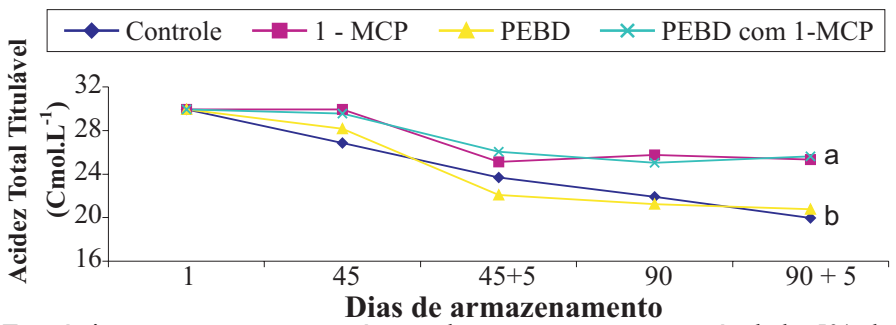

Estatística para uma mesma época de armazenagem, ao nível de 5\% de probabilidade pelo teste de Tukey.

FIGURA 3 - Acidez titulável de kiwis cv. Bruno, armazenados 90 dias sob refrigeração a $0 \pm 0,5^{\circ} \mathrm{C}$ e $95 \pm 3 \%$ de UR mais 5 dias de simulação de comercialização a $22 \pm 3^{\circ} \mathrm{C}$ e $75 \pm 5 \%$, Farroupilha/RS-2001.

se diminuir as perdas nos teores de AT dos frutos, sugerindo portanto, uma menor atividade metabólica dos frutos. Resultados semelhantes foram encontrados por Waclawovsky et al. (2001), onde a AT dos frutos não tratados com o 1-MCP decresceu mais rapidamente durante o AR, em relação à acidez dos frutos tratados com o 1-MCP. Do mesmo modo, Fan et al (1999b), trabalhando com maçãs "Granny Smith", "Red Chief Delicious" e "Fuji", tratadas com 1-MCP, alcançaram excelente manutenção da FP e da AT, em comparação com os frutos não tratados.

A concentração de $\mathrm{CO}_{2}$ presente nas embalagens de PEBD (Figura 4), medida aos 45 e 90 dias, foi influenciada significativamente pela ação do 1-MCP. Nas embalagens em que o frutos foram tratados com 1-MCP, observaram-se as menores concentrações, em média 0,62 e $0,64 \mathrm{kPa}$, aos 45 e 90 dias respectivamente, enquanto que nas embalagens onde os frutos não foram submetidos ao tratamento com o 1-MCP, observaram-se no mesmo período, 1,25 e 1,17 kPa, ou seja, um padrão respiratório mais elevado em relação aos frutos tratados com o 1-MCP, indicando portanto, neste caso, a eficácia do 1-MCP quanto à desaceleração da atividade respiratória dos frutos. Jiang et al. (1999), em seus estudos, relacionam a contenção da velocidade do amadurecimento dos frutos com o atraso no início da elevação dos níveis respiratórios. No mesmo sentido, Waclawovsky et al. (2001) comprovaram a eficiência do 1-MCP, quanto ao atraso na evolução das concentrações de $\mathrm{CO}_{2}$, mesmo em kiwis submetidos à exposição ao etileno, mantendo-se com as menores concentrações de $\mathrm{CO}_{2}$ quando comparados aos frutos controle.

Da mesma forma, o 1-MCP influenciou positivamente na diminuição da concentração de etileno nas embalagens (Figura 5). As maiores concentrações, medidas aos 45 e 90 dias de AR, foram detectadas nas embalagens onde os frutos não foram tratados com o 1-MCP $(3,45$ e $3,23 \mathrm{kPa}$, respectivamente) e, as menores concentrações nas embalagens onde os frutos foram tratados com 1-MCP $(0,04$ e $0,16 \mathrm{kPa}$, respectivamente). Como os kiwis são altamente sensíveis a ação do etileno, além da redução na concentração de etileno nas embalagens, o

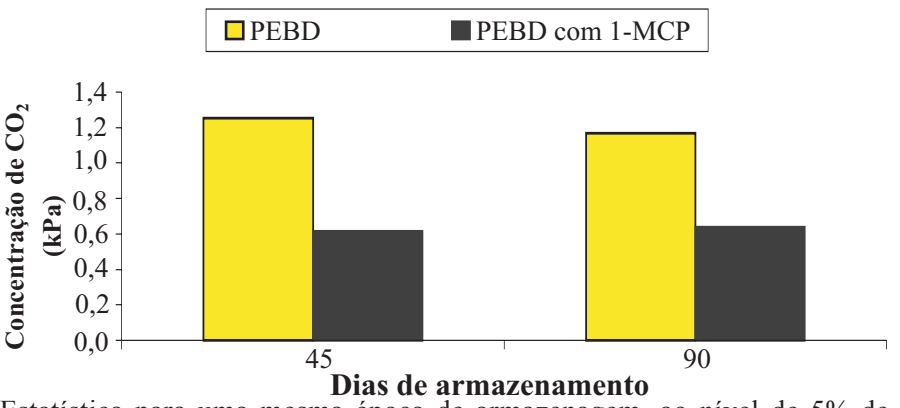

Estatística para uma mesma época de armazenagem, ao nível de 5\% de probabilidade pelo teste de Tukey.

FIGURA 4 - Concentração de $\mathrm{CO}_{2}$, nas embalagens de kiwis cv. Bruno, aos 45 e 90 dias de armazenamento sob refrigeração a $0 \pm$ $0,5^{\circ} \mathrm{C}$ e $95 \pm 3 \%$ de UR, Farroupilha/RS -2001 .

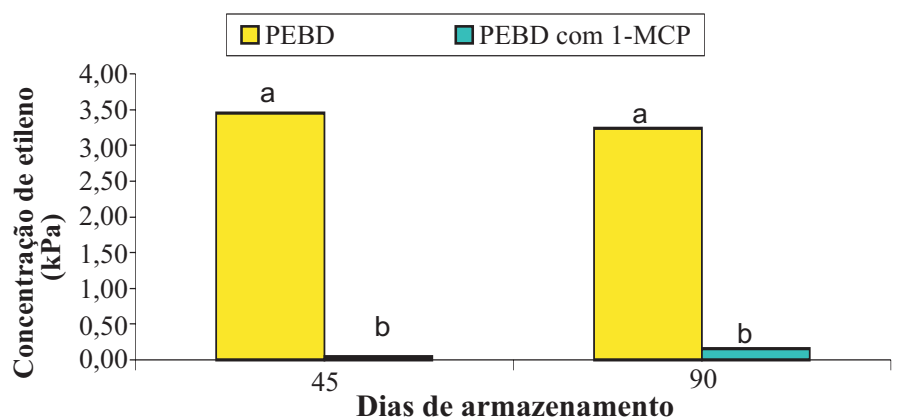

Estatística para uma mesma época de armazenagem, ao nível de 5\% de probabilidade pelo teste de Tukey.

FIGURA 5 - Concentração de etileno, nas embalagens de kiwis cv. Bruno, aos 45 e 90 dias de armazenamento sob refrigeração a $0 \pm$ $0,5^{\circ} \mathrm{C}$ e $95 \pm 3 \%$ de UR, Farroupilha/RS -2001 .

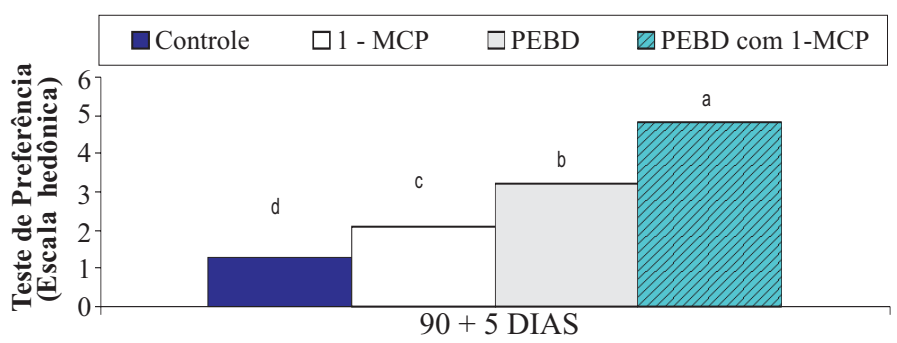

Dias de Armazenamento

Estatística para uma mesma época de armazenagem, ao nível de 5\% de probabilidade pelo teste de Tukey.

FIGURA 6 - Teste de preferência, através de análise sensorial - escala hedônica (1 a 5), em kiwis cv. Bruno, aos 90 dias de armazenamento sob refrigeração a $0 \pm 0,5^{\circ} \mathrm{C}$ e $95 \pm 3 \%$ de UR mais 5 dias de simulação de comercialização $22 \pm 3{ }^{\circ} \mathrm{C}$ e $75 \pm 5 \%$, Farroupilha/RS -2001 .

1-MCP proporcionou benefícios tecnológicos aos frutos, principalmente quanto à preservação da FP. O mesmo verifica-se citado por Jiang et al. (1999, 2001), onde é descrito que o 1-MCP inibe a ação do etileno, em baixas concentrações $(\mathrm{nL} / \mathrm{L})$ e, aumenta a vida de prateleira de frutos e hortaliças. Feng et al. (2000), trabalhando com abacates cvs 'Hass', 'Reed' e 'Fuerte' e Fan \& Mattheis (2001), trabalhando com maçãs cv. Gala, também mencionaram o efeito positivo do 1-MCP no controle da ação do etileno e conseqüentemente no prolongamento da vida útil dos frutos.

Pelo teste de preferência (Figura 6), observou-se que 90 dias de AR mais 5 dias de comercialização simulada, os frutos acondicionados nas embalagens de PEBD e tratados com o 1-MCP, apresentaram os melhores índices de preferência pelos julgadores, enquanto que nos frutos-controle, o avançado estádio de amadurecimento e conseqüente perda da qualidade sensorial, levou os julgadores à rejeição destes 
frutos. Resultados intermediários foram obtidos nos frutos somente acondicionados nas embalagens de PEBD e nos frutos sem embalagens e tratados com o 1-MCP. Fica portanto evidenciado a interação positiva AM, através da embalagem de PEBD em associação com o 1-MCP (Jiang et al., 1999), no que diz respeito a preservação da qualidade sensorial dos frutos mesmo após a retirada do AR.

\section{CONCLUSÕES}

A utilização da atmosfera modificada, através do acondicionamento dos frutos em embalagens de PEBD com $22 \mu \mathrm{m}$ de espessura, associada ao tratamento dos frutos com o 1-MCP, na concentração de $625 \mathrm{ppb}$, proporciona um período seguro de $\mathrm{AR}$ de 90 dias para kiwis da cv. Bruno, com adequada manutenção dos atributos sensoriais de qualidade.

\section{REFERÊNCIAS BIBLIOGRÁFICAS}

CAMERON, A. C.; REID, M. S. The use of silver thisulfate anionic complex as a foliar spray to prevent flower abscission of zygocactus. HortScience, Alexandria, v.16, n.6, p.761-762, 1981.

FAN, X.; BLANKENSHIP, S. M.; MATTHEIS, J. P. 1Methylcyclopropene inhibits apple ripening. Journal of the American Society for Horticultural Sciense, Alexandria, v.124, n.6, p.690-695. 1999a.

FAN, X.; BLANKENSHIP, S.; MATTHEIS, J. Development of apple superficial scald, soft scald. core flush and greasiness is reduced by MCP. Journal of Agricultural and Food Chemistry, Washington, n. 47, p. 3063-3068. 1999b.

FAN, X.; ARGENTA, L.; MATTHEIS, J.; Responses of "D'Anjou” and "Bartlett" pear fruit to postharvest 1-methylcyclopropene (MCP) treatment. HortScience, Alexandria, v. 3, n.34, p.507, 1999c. (abstract)

FAN, X.; MATTHEIS, J.P. 1-Methylcyclopropene and storage temperature influence responses of 'Gala' apple fruit to gamma irradiation. Postharvest Biology and Technology, Amsterdan, n. 23, p. 143-151, 2001.

FAN, X.; ARGENTA, L.; MATTHEIS, J.; Interactive effect of 1-MCP and temperature on "Elberta" peach quality. Postharvest Biology and Technology, Amsterdan, n.37, v.1, p.134-138, 2002.

FENG X.;APELBAUM,A.; SISLER, E.C.; GOREN, R. Control of ethylene responses in avocado fruit with 1-methylcyclopropene. Postharvest Biology and Technology, Amsterdan, n.20, p.143-150, 2000.

GOLDING J. B.; SHEARER, D.; WYLLIE, S. G.; MCGLASSON, W. B. Application of 1-MCP and propylene to identify ethylene-dependent ripening processes in mature banana fruit. Postharvest Biology and Technology, Amsterdan, n.14, p.87-98. 1998.

JIANG, Y.; JOYCE, D. C.; MACNISH, A. J. Extension of the shelf life of banana fruit by 1-methylcyclopropene in combination with polyethylene bags. Postharvest Biology and Technology, Amsterdan, n.16, p.187-193. 1999.
JIANG Y.; JOYCE, D.C.; TERRY, L.A. 1-Methylcyclopropeno treatment affects strawberry fruit decay. Postharvest Biology and Technology, Amsterdan, n.23, p.227-232. 2001.

KIM, H.O.; HEWETTL, E.W.; LALLU, N. Softening and ethylene production of kiwifruit reduced with 1-metylcyclopropene. In: INTERNATIONAL CONFERENCE ON POSTHARVEST SCIENCE -POSTHARVEST, 4., 2000, Jerusalem. Abstracts... Jerusalem: ISHS, 2000.p. 21

LEGARRAGA, D.M. Cosecha, conservación y normas de embalaje de kiwis. In: SIMPÓSIO BRASILEIRO DA CULTURA DO KIWI, 1., 1994, Farroupilha. Anais.... Bento Gonçalves: EMBRAPA/CNPUV, 1994. p. 25-29.

MORAES, M.A.C. Métodos para avaliação sensorial dos alimentos. 6ed. Campinas: Editora Unicamp, 1988.

MOSCA, J. L.; MUGNOL, M. M.; VIEITES, R. L. Atmosfera modificada na pós-colheita de frutas e hortaliças. Botucatu: FEPAF, 1999. 28p.

NEVES, L.C.; RODRIGUES, A.C.; VIEITES, R.L. Polietileno de baixa densidade (PEBD) na conservação pós-colheita de figos cv. "Roxo de Valinhos". Revista Brasileira de Fruticultura, Jaboticabal, v.24, n.1, p.57-62, 2002.

SENTER, S D.; CHAPMAN, G.W., FORBUS, W.R.; PAYNE, J.A. Sugar and non-volatile acid composition al persimmons during maturation. Journal of Food Science, Chicago, n.56, p.989-991, 1991.

SEREK, M.; SISLER, E. C.; REID, M.S. Novel gaseous ethylene biding inhibitor prevents ethylene effects in potted flowering plants. Journal of the American Society for Horticultural Sciense, Alexandria, v.119, n.6, p.1230-1233. 1994.

SIMÃO, S. Tratado de fruticultura. Piracicaba: FEALQ. 1998. 760p.

SISLER, E. C.; SEREK, M.; DUPILLE, E. Comparison of cyclopropene, 1-methylcyclopropene and 3,3-dimethylcyclopropene as ethylene antagonists in plants. Plant Growth Regulation, Dordrecht, v.18, p.169-174. 1996.

SISLER, E.C.; SEREK, M. Inhibitors of ethylene responses in plants at the receptor level: recent developments. Plant Physiology, Bethesda, v.100, p.577-582. 1997.

SMITH, R. B. Controlled atmosphere storage of "Redcoat" strawberry fruit. Journal of the American Society for Horticultural Sciense, Alexandria, v.117, p.260-264, 1992.

SOUZA, P. V. D.de; MARODIN, A.B.; NOGUEIRA, B. Cultura do quivi. Porto Alegre: Cinco continentes.1996. p.104.

WACLAWOVSKY, A.J.; DONAZZOLO, J.; NEUWALD, D.A.; BRACKMANN, A. Qualidade pós-colheita de kiwis (Actinidia deliciosa, Chevalier), cv. Bruno, tratados com 1-metilciclopropeno (1-MCP). In: CONGRESSOBRSILEIRODE FISIOLOGIA VEGETAL, 8., 2001, Ilhéus. Anais... Ilhéus: SBFV: Ilhéus, 2001. CD-ROM 4-030.

WARRINGTON, I.J., WESTON, GC. Kiwifruit science and management. Auckland: Ray Richards Publisher, 1990. 576p.

WILLIS, R. B. H.; KIM, G. H. Effect of ethylene on postharvest life of strawberries. Postharvest Biology and Technology, Amsterdan, v.6,p.249-255. 1995. 